\title{
Batik Incung dan Islam di Kerinci
}

\author{
Nandia Pitri \\ Program Magister, Universitas Andalas \\ e-mail: nandpitri@gmail.com
}

\begin{abstract}
ABSTRAK. Artikel ini membahas tentang motif batik incung. Jenis apa batik incung itu? Apa adakah budaya dibalik motif batik incung? Metode penelitian yang digunakan adalah pendekatan historis untuk menemukan sejarah dari batik incung. Siapa saja aktor yang melakukan perubahan budaya di Kerinci, terutama terkait dengan kemunculan motif batik incung yang berkaitan dengan islam. Berdasarkan sejarah, akan diketahui mengapa batik incung memiliki motif seperti itu. Hasil penelitian menunjukkan bahas berdasarkan sejarah Kerinci, motif batik mendapat pengaruh dari islam. Batik incung merupakan batik asli dari masyarakat Kerinci. Batik ini disebut sebagai batik incung karena kekhasannya menggunakan aksara incung sebagai motif utama. Aksara incung adalah aksara Kerinci kuno yang digunakan untuk menulis tambo, tanah wilayah suku, hukum adat, kesastraan suci, surat cinta, pantun, mantra-mantra dan kutukan yang dituliskan pada kulit kayu, tanduk kerbau, tanduk sapi, daun lontar, bambu dan kertas. Seiring dengan perkembangannya, aksara incung dijadikan sebagai motif batik di Kerinci yang dilakukan agar masyarakat mudah untuk memahami makna yang terkandung dalam aksara tersebut. Hubungan antara batik incung dengan Islam di Kerinci ini adalah ada beberapa motif incung yang digabungkan dengan unsur-unsur Islam. Motif-motif yang mengandung unsur islam, seperti kaligrafi incung, masjid agung Pondok Tinggi dan sebagainya.
\end{abstract}

Kata kunci: batik, incung, islam, Kerinci.

\section{PENDAHULUAN}

Kerinci merupakan salah satu wilayah yang berada dalam kawasan Provinsi Jambi yang dijuluki sebagai wilayah segumpal tanah dari surga (Kartini). Hal ini disebebkan karena perbukitan dengan puncak yang tinggi serta sungai yang jernih dan tanah yang subur. Kondisi geografis inilah yang menjadikan wilayah Kerinci memiliki daya tarik masyarakat untuk mendiami wilayah ini, sehingga membawa dampak bagi masyarakat asli Kerinci seperti bidang budaya (bahasa, tingkah laku), ekonomi (pola kehidupan) dan sosial (adat istiadat). Keunikan dari masyarakat Kerinci ini karena mereka berpegang teguh pada adat istiadat yang mereka miliki, sehingga perubahan yang terjadi tidak terlalu mempengaruhi kebudayaan yang mereka miliki (Kartini).

Salah satu kebudayaan yang masih dimiliki oleh masyarakat Kerinci adalah aksara incung. Aksara incung merupakan aksara kerinci kuno yang dahulunya digunakan oleh masyarakat kuntum menulis mantra-mantra pada daun lontar, tandu kerbau, dan kayu. Seiring dengan perkembangannya, aksara incung dijadikan sebagai motif batik bagi masyarakat Kerinci. Aksara incung mempunyai dua sisi yang bisa dikembangkan yaitu bahasa dan seni. Hal inilah yang menyebabkan incung dikembangkan oleh masyarakat untuk menjadi motif 
batik khas Kerinci. Selain itu, perkembangan aksara incung dalam masyarakat Kerinci juga dipengaruhi oleh ajaran Islam yang berkembang di tengah kehidupan masyarakat, salah satu yang mendapat pengaruh yaitu adanya tulisan incung yang berlafazkan "Assalamualaikum" yang ditemukan oleh peneliti. Hal inilah yang menjadi penyebab bahwa permasalahan penelitian ini perlu untuk ditelusuri lebih mendalam.

\section{METODOLOGI}

Penelitian ini menggunakan metode penelitian sejarah yang terdiri dari empat tahapan yakni heuristik, kritik, interpretasi dan historiografi (Gottschalk). Mestika Zed mengatakan bahwa metode sejarah adalah proses menguji dan menganalisis secara kritis rekaman peninggalan masa lampau berdasarkan data yang diperoleh dengan menempuh proses yang berwujud historiografi. Dalam hal ini metode sejarah digunakan agar dapat merekonstruksi kembali peristiwa masa lampau, sehingga dapat di uji kebenarannya (Zed). Tahap pertama, yakni heuristik (pengumpulan sumber). Sumber-sumber yang didapatkan dari hasil studi perpustakaan dan hasil wawancara dengan pelaku sejarah yang dapat dijadikan sebagai informan. Studi pustaka dilakukan ke berbagai perguruan tinggi yang ada di Sumatera Barat, khsusnya Kota Padang. Seperti penelusuran pustaka pusat Universitas Andalas, pustaka pascasarjana Universitas Andalas, pustaka jurusan Magister Universitas Andalas serta pustaka pusat Universitas Negeri Padang, kemudian tak ketinggalan perpustakaan daerah Sumatera Barat. Arsip dan perpustakaan Kerinci, selanjutnya sumber penting lainnya dapat ditemukan di kantor Dinas Perindustrian dan Perdagangan Kabupaten Kerinci dan Kota Sungaipenuh, Badan Pusat Statistik Kabupaten Kerinci dan Kota Sungaipenuh, dan Dinas Parawisata Kabupaten Kerinci dan Kota Sungaipenuh. Selain menggunakan Sumber tulisan, sumber lisan yaitu wawancara dilakukan kepada pelaku sejarah yang masih hidup yang terlibat langsung dengan industri batik incung dan budayawan yang ada di Kota Sungaipenuh. Diantaranya, Elita Jaya, Deli Iryani, Erni Yusnita, Depati H. Alimin. Setelah sumber data terkumpul, langkah selanjutnya adalah dengan melakukan kritik sumber melalui kritik ekstern dan kritik intern agar memperoleh kredibilitas dan otentisitas. Fakta sejarah kemudian diinterpretasikan atau penafsiran sesuai dengan pendekatan budaya. Tahap terakhir adalah historiografi yaitu penulisan fakta-fakta yang diperoleh dari data-data yang ada. Proses penulisan dapat disatukan sehingga menjadi satu perpaduan yang sistematis dalam bentuk narasi kronologis (Sjamsuddin).

\section{HASIL PENELITIAN DAN PEMBAHASAN}

\section{Kerinci dalam Kisaran Sejarah}

Kerinci merupakan kawasan yang terletak pada dataran tinggi pegunungan bukit barisan. Keadaan alamnya yang terdiri dari gugus pegunungan dan lembah membuat kawasan ini ditutupi oleh hutan belantara yang memiliki keragaman hayati (Ramli dan Ayu). Kondisi geografis Kerinci inilah yang mempengaruhi pengrajin batik dalam menggunakan motif batik di Kerinci. Hal ini disebabkan karena motif batik yang digunakan oleh para pengrajin adalah motif flora dan fauna serta aksara incung dan ragam hias yang ada di Kerinci. Motif batik di Kerinci dikatakan beragam sesuai dengan keberagaman hayati yang dimiliki oleh alamnya. 
Masyarakat yang mendiami alam Kerinci ini disebut suku Kerinci yang merupakan masyarakat pribumi yang sudah mendiami wilayah ini ribuan tahun silam. Menurut penelitian sejarah, suku Kerinci berasal dari Proto Melayu (Melayu tua) yang datang dari Asia Tenggara pada 3000-2000 SM (Vrihaspathi dan Ekaputra). Selain suku asli Kerinci, wilayah ini juga dihuni oleh beberapa suku bangsa seperti Minangkabau, Jawa, Batak, Palembang, Tionghoa dan lain sebagainya. Suku Minangkabau datang ke wilayah Kerinci ini pada abad ke-13 yang dibawakan oleh keluarga kerjaan Minangkabau. Selain itu, pada dahulunya Kerinci merupakan bagian dari Minangkabau. Hubungan Kerinci dengan Minangkabau ini dapat dilihat dari beberapa aspek yaitu aspek geopolitik, ekonomi dan genealogis. Aspek geopolitik, Kerinci dengan Minangkabau (Indrapura) merupakan satu kesatuan antara pesisir pantai atau muara sungai dengan pedalaman atau dataran tinggi serta politik di antara kesultanan tersebut yang berusaha untu membuat Kerinci menjadi bagian dari wilayahnya. Aspek ekonomi, Kerinci merupakan daerah pegunungan yang menghasilkan hasil pertanian seperti beras serta Indrapura merupakan wilayah pesisir pantai yang bisa memenuhi kebutuhan masyarakat daerah pegunungan dalam pemenuhan garam, ikan dan lain sebagainya. Sedangkan pada aspek genealogis adanya perkawinan antara seorang raja dari Indrapura dengan perempuan Kerinci sehingga membuat hubungan antara kedua wilayah ini semakin dekat (Syaputra).

Suku Jawa mendiami daerah Kerinci karena pada masa Pemerintah Hindia Belanda adanya pembukaan lahan perkebunan di Kerinci sehingga suku Jawa yang datang ke Kerinci untuk dipekerjakan pada perkebunan teh Kayu Aro. Sementara itu, suku Batak, Palembang, dan lainnya masuk ke wilayah Kerinci ini disebabkan karena adanya kegiatan ekonomi yaitu perdagangan (Jambi).

\section{Asal Usul Nama Kerinci}

Asal usul nama Kerinci berasal dari beberapa pendapat. Pendapat pertama menyebutkan bahwa seseorang yang bernama Datuk Paduko Berhalo yang tinggal di tepi Danau Kerinci (sekarang Sanggaran Agung) yang kehilangan kunci yang jatuh ke dalam sungai serta berjuang untuk menemukannya dengan susah payah. Dia akhirnya mendapatkan kunci miliknya sehingga sungai tersebut diberi nama Batang Kunci yang populer disebut sebagai Batang Kerinci ("batang” dalam bahasa lokal berarti sungai) (Zakaria, Tambo Sakti Alam Kerinci 3).

Pendapat kedua menyatakan bahwa Kerinci berasal dari bahasa Jawa yang berarti kering dan ji berarti sungai kering. Maka dari kata Keringci lebih dikenal oleh masyarakat sebagai Kerinci. Pendapat ketiga disebut sebagai Kerinci karena terletak pada dataran tinggi yang dikelilingi oleh bukit baris. Sehingga, pada musim panas akan kering sedangkan pada musim hujan akan cair. Maka dari sanalah didapatkan kata Kerinci yang berasal dari kata kering dan cair. Pendapat keempat menyatakan bahwa keadaan alam yang dibatasi oleh bukit barisan serta hutan lebat menyebabkan daerah ini sulit untuk dilewati sehingga disebut sebagai daerah terkunci yang pada akhirnya disebut sebagai Kerinci (Zakaria, Tambo Sakti Alam Kerinci 3).

\section{Peradaban Masyarakat Kerinci}


Asal usul masyarakat Kerinci terdiri dari beberapa pendapat. Pertama, masyarakat Kerinci merupakan orang-orang yang datang dari India belakang (Asia Tenggara) dan Mongolia, mereka datang beriringan dengan kedatangan bangsa yang menyebar ke seluruh nusantara. Sementara itu, mereka sampai di Kerinci melewati Semenanjung Melayu (sekarang Malaysia), melintasi Selat Malaka, pergi ke pantai timur Sumatera ke selatan dan berbelok ke Sungai Batang Hari sampai ke Sungai Batang Merangin lalu ke Kerinci. Namun, sesampainya mereka di Kerinci sudah ada orang yang mendiami daerah tersebut tetapi tempat asal mereka tidak diketahui. Pendapat ini memperkuat anggapan bahwa Suku Bangsa Kerinci lebih tua jika dibandingkan dengan suku bangsa INCA (Indian) yang dibuktikan dengan manusia Kecik Wok Gedang Wok yang belum memiliki nama panggulan secara individu. Sementara suku Indian sudah memiliki nama seperti Big Buffalo (kerbau besar), Little Fire (api kecil) (Vrihaspathi dan Ekaputra).

Kedua, masyarakat asli Kerinci berasal dari Papua Melaneoid yang datang setengah juta tahun yang lalu. Keturunan yang tersisa dari suku ini yang masih ditemukan di Indonesia adalah mereka yang tinggal di daerah pedalaman seperti Suku Kubu di pedalaman Suamtera dan Suku Pagai di pulau Mentawai. Sementara di Kerinci, suku ini telah punah dan di duga mereka menyebar lebih jauh ke pedalaman Sumatera (Zakaria, Tambo Sakti Alam Kerinci 3).

Ketiga, bahwa kedatangan suku Kerinci ini terjadi selama nirleka pada masa Paleolitikum dan Mesolitikum sekitar 10.000 tahun SM. Sementara itu, pada masa Neolitikum, suku Kerinci datang dari daerah Yunan di Cina dengan dua gelombang, yaitu etnis Austronesia Melayu. Gelombang pertama adalah Proto Melayu (6.000 hingga 2.000 SM selama zaman batu), sedangkan gelombang kedua adalah Deutro Melayu (2.000 hingga 3.000 SM dari batu muda sampai ke zaman perunggu atau logam) (D. P. Kebudayaan).

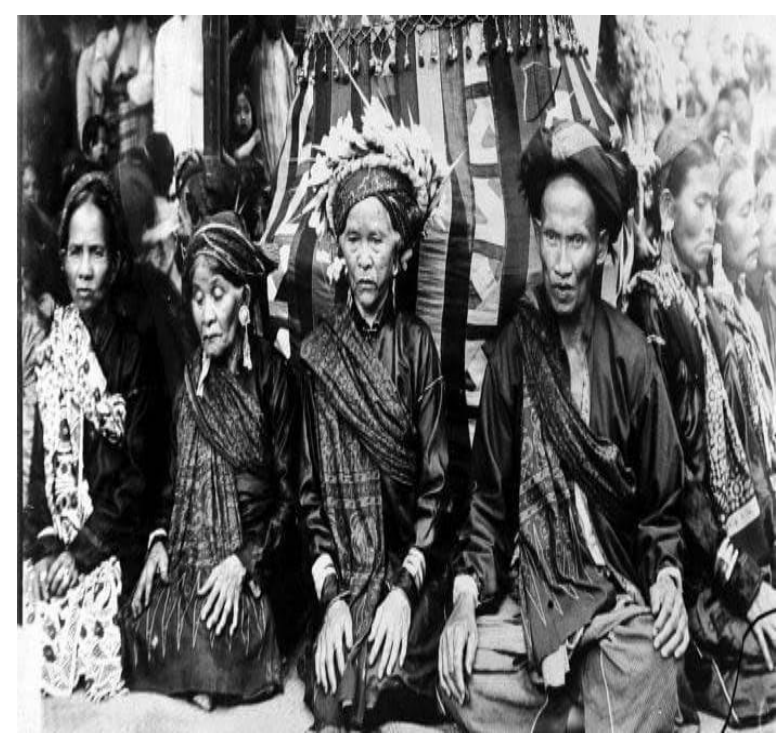

Gambar 1. Orang Kecik Wok Gedang Wok (asli dataran tinggi bukit barisan).

(Vrihaspathi, 2013: 6)

Pendapat tentang asal usul masyarakat Kerinci ini yang paling banyak diterima adalah pendapat pertama yang menyatakan bahwa masyarakat Kerinci berasal dari India Belakang 
(Asia Tenggara) dan Mongolia yang datang bersama bangsa-bangsa yang menyebar ke seluruh pelosok nusantara (Zakaria, Tambo Sakti Alam Kerinci 3).

\section{Kebudayaan Masyarakat Kerinci}

Menurut Clifford Geertz (Abdullah) kebudayaan adalah pola dari makna yang terjalin menyeluruh melalui simbol dan diterapkan secara historis. Kebudayaan sering dianggap sebagai kompas atau pedoman bertingkah laku dalam perjalanan hidup manusia. Selain itu, kebudayaan diartikan juga sebagai konsep yang diwariskan secara simbolik sehingga manusia dapat berkomunikasi, melestarikan serta mengembangkan pengetahuan dan sikapnya terhadap kehidupan yang dijalaninya.

Masyarakat Kerinci merupakan penduduk asli yang mendiami wilayah Kerinci sejak masa silam. Keadaan sosial budaya masyarakatnya ditandai dengan suku Kerinci yang merupakan keturunan dari suku Melayu tua yang menetap sejak zaman mesolitikum serta mempunyai bahasa dan dialek spesifik (bahasa Kerinci) yaitu aksara incung.

Wilayah Kerinci merupakan daerah pertaninan terluas dalam kawasan Taman Nasional Kerinci Sebelat (TNKS) serta merupakan wilayah yang subur dan relatif terisolir. Hal ini menyebabkan perkembangan kebudayaan yang ada di wilayah ini lebih menunjukkan sifat religius serta penghormatan pada peninggalan nenek moyang mereka. Menurut Alimin (budayawan Kerinci) hubungan kekerabatan lebih erat dan terikat satu sama lainnya dilihat dari adanya strata dalam masyarakat, seperti tuo-tuo teganai (tokoh masyarakat, Ninik mamak, kaum adat), alim ulama, cerdik pandai, dan masyarakat biasa baik yang muda maupun yang tua.

Peninggalan budaya di wilayah Kerinci merupakan aset budaya yang dimiliki oleh wilayah setempat, seperti masjid keramat, masjid agung, masjid kuno, pernik tembikar, aksara incung, dan batu bersurat. Sementara itu, ada juga kegiatan budaya yang masih dipakai oleh wilayah Kerinci ini seperti pelaksanaan adat istiadat yang secara turun temurun, seperti perkawinan, khitanan, kematian, turun ke sawah, panen, mendirikan rumah, kenduri sko, dan lain sebagainya yang dilaksanakan oleh masyarakat dengan cara gotong royong.

Berdasarkan uraian di atas terlihat bahwa manusia sebagai pencipta kebudayaan. Hal ini berarti, kebudayaan adalah keseluruhan sistem gagasan, tindakan dan hasil karya manusia untuk memenuhi kehidupannya. Sementara itu, masyarakat Kerinci mempunyai tradisi bapenteh. Tradisi bapenteh adalah tradisi membuat hiasan dinding pada acara perkawinan di rumah calon mempelai perempuan. Hiasan yang digunakan pada saat itu adalah kain yang disusun dan dijalin dengan rapi, dan kain yang digunakan berupa kain panjang katun dan bermotif batik dengan beragam warna. Kain yang disusun rapi ini berfungsi sebagai pelaminan di rumah calon pengantin perempuan (Ramadani). Dengan demikian, kain batik bagi masyarakat Kerinci sudah tidak asing lagi karena sudah mengenalnya sejak masa silam yang dijadikan sebagai hiasan dinding di rumah calon mempelai perempuan pada saat acara pernikahan.

Ada beberapa unsur dalam kebudayaan, salah satunya adalah bahasa. Bahasa yang digunakan oleh masyarakat Kerinci adalah bahasa Kerinci (aksara incung). Aksara ini adalah salah satu peninggalan peradaban masa silam yang terdapat di Sumatera adalah kesastraan incung yang memakai aksara daerah Kerinci. Wilayah induk penyebaran aksara daerah yang memiliki ciri-ciri tersendiri ada 4, yaitu Batak, Kerinci, Rejang dan Lampung. Satu-satunya wilayah yang memiliki aksara sendiri di Sumatera bagian tengah adalah Kerinci. Hal ini 
dibuktikan dengan adanya naskah kuno yang menggunakan aksara incung. Bahasa yang digunakan adalah bahasa Kerinci kuno yaitu lingua Francis suku Kerinci zaman dahulu (D. P. Kebudayaan).

Aksara incung adalah aksara kuno yang digunakan untuk menulis tambo, tanah wilayah suku, hukum adat, kesastraan suci, surat cinta, pantun, mantra-mantra dan kutukan yang dituliskan pada kulit kayu, tanduk kerbau, tanduk sapi, daun lontar, bambu dan kertas (D. P. Kebudayaan).
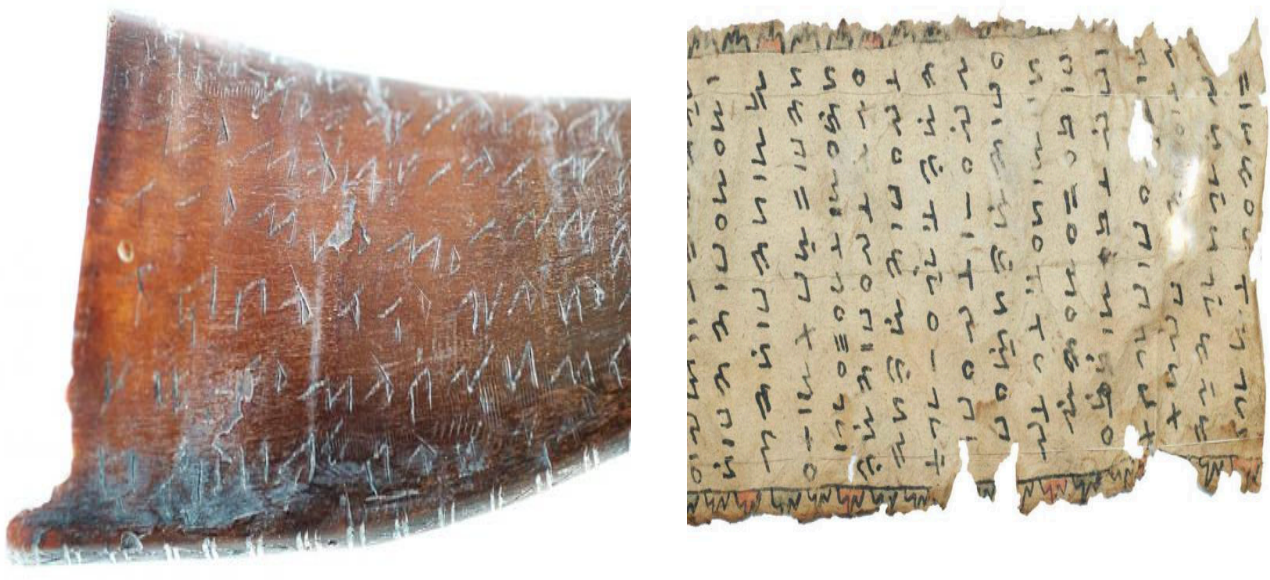

Gambar 2. Aksara Incung yang Dituliskan pada Tanduk Kerbau, Tanduk Sapi, Bambu dan Kertas

(Dokumentasi Hafiful Hadi dalam Kompasania, yang diakses melalui https://www.kompasiana.com/hafifulhadi/590072eb509773ad01e70eb5/aksara-suratincung-riwayat-dan-problematikanya?page=all)

Aksara incung Kerinci dibentuk oleh garis-garis lurus, patah terpancung dan melengkung. Kemiringan garis pembentuk huruf itu diperkirakan rata-rata $45^{\circ}$. Meskipun demikian, dalam aksara incung Kerinci ini tidak berarti aksara yang ditulis miring, seperti dalam penulisan huruf latin yang ditulis miring bersambung, tetapi kebanyakan naskahnaskah tulisan incung yang disimpan orang Kerinci fungsinya sebagai pusaka yang dikeramatkan. Naskah kuno aksara incung Kerinci, pada awalnya ditulis dengan memakai sejenis benda runcing dan guratannya mirip dengan tulisan paku aksara Babilonia Kuno. Naskah kuno aksara incung Kerinci sudah dipergunakan oleh orang Kerinci selama berabadabad sesudah aksara Pallawa dikenal oleh bangsa Melayu Sumatera (Alimin, Sastra Incung Kerinci). 


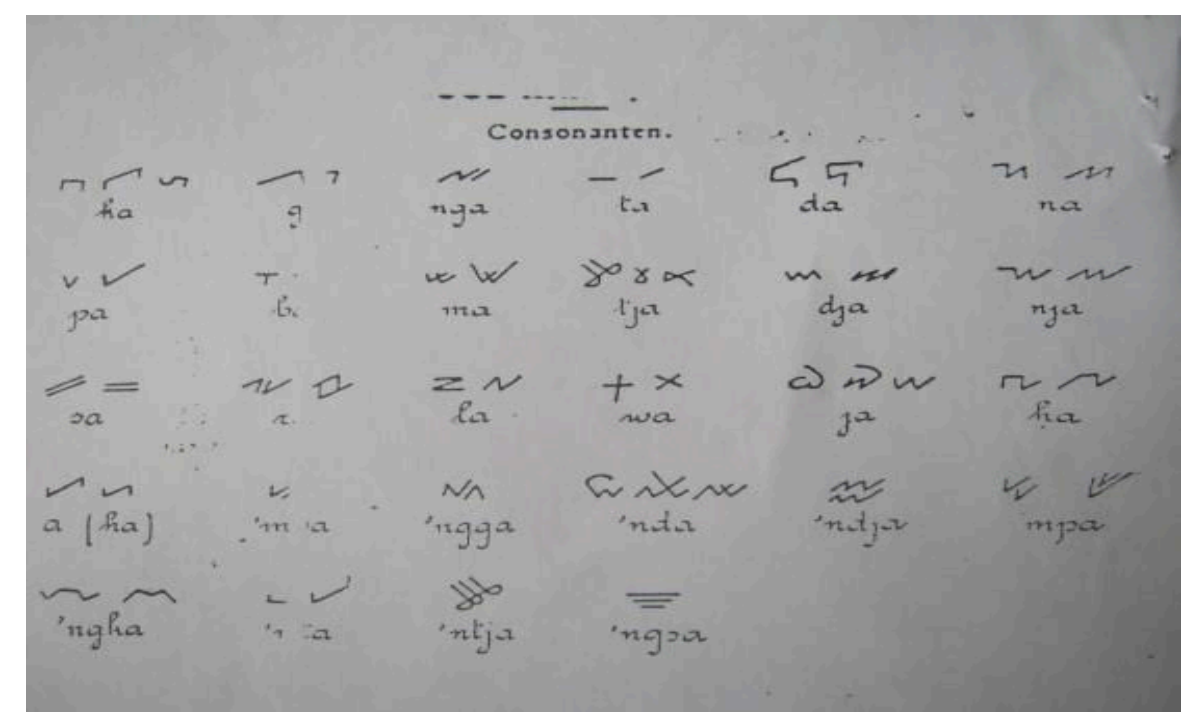

Gambar 3. Abjad aksara incung

(Dokumentasi Hafiful Hadi dalam Kompasania, yang diakses melalui

https://www.kompasiana.com/hafifulhadi/590072eb509773ad01e70eb5/aksara-suratincung-riwayat-dan-problematikanya?page=all)

Aksara incung berkembang di Kerinci atau dataran tinggi sebelum Islam masuk ke wilayah ini. Kozok juga menjelaskan perbedaan antara aksara incung dengan aksara kuno yang berkembang di wilayah Sumatera, seperti aksara Rencong di Rejang Lebong, dan aksara Lampung (Kozok).

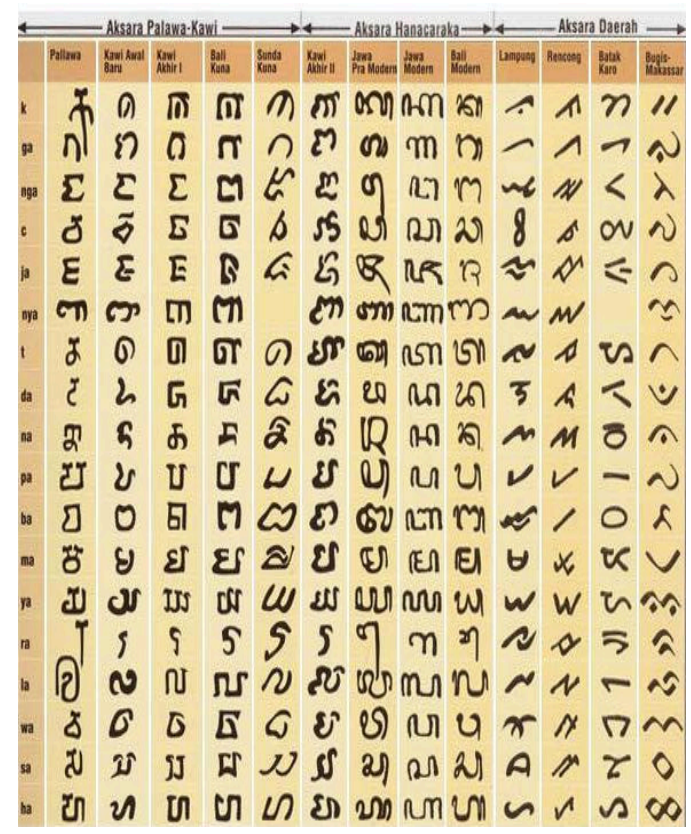

Gambar 4. Ragam Aksara Kuno Nusantara

(Dokumentasi Hafiful Hadi dalam Kompasania, yang diakses melalui https://www.kompasiana.com/hafifulhadi/590072eb509773ad01e70eb5/aksara-suratincung-riwayat-dan-problematikanya?page $=$ all)

Walaupun aksara incung memiliki persamaan bentuk dengan aksara-aksara lainnya di Sumatera, namun aksara incung Kerinci memiliki karakteristik tersendiri karena sebutannya sebagai huruf miring, yang berbeda dengan daerah lainnya tidak menyebabkan aksara kuno 
sebagai huruf miring. Sementara itu, perkembangan aksara incung semakin hari kian pesat yang ditandai dengan dimasukkannya aksara incung menjadi motif batik di Kerinci.

\section{Islam di Kerinci}

Suku Kerinci merupakan suku yang religius dan selalu teguh terhadap nilai-nilai Islam dalam kehidupan sehari-hari. Pada umumnya, suku Kerinci beragama Islam hanya kelompok etnis tertentu yang beragama non Islam yang berada di Kerinci. Sebelum Islam dikenal oleh suku Kerinci, mereka sudah mengenal kepercayaan animisme dan dinamisme serta dipengaruhi oleh agama Hindu Budha dan Islam (Djakfar dan Indra, Menguak Tabir Prsejarah di Alam Kerinci).

Islam berkembang di Kerinci diyakini pada abad ke 13 M. Islam masuk pada masa kekuasaan "Sagindo" (abad 13 M sampai abad 19 M) yang dibawakan oleh tujuh orang Siak, yaitu Siak Jelir di Koto Jelir (Siulak), Siak Rajo di Sungai Medang, Siak Ali di Koto Bingin (Sungai Liuk), Siak Lengeh di Koto Pandan (Sungaipenuh), Siak Sati di Koto Jelatang (Hiang), Siak Beribut di Koto Merantih (Tarutung), dan Siak Ji (Haji) d Lunang (Djakfar, Hukum Waris Adat Kerinci). Keterangan ini didukung dengan adanya tambo yang bertuliskan aksara Rencong Kerinci, terdapat kalimat “Assalamualaikum” seperti ditemukan pada tambo Datuk Singarapi Putih Sungaipenuh (Schrieke). Hal inilah yang membuktikan bahwa terdapat pengaruh Islam dalam Tambo Kerinci dengan sebagian penduduknya telah memeluk Islam.

Asal usul kedatangan tujuh orang siak mempunyai beberapa pendapat. Pertama, kedatangan ketujuh orang siak berasal dari Kerajaan Siak yaitu kerajaan yang terletak di wilayah Riau. Hal ini dibuktikan dengan sebutan siak yang menunjukkan kerajaan yang ada di Riau tersebut (Martunus). Kerajaan Siak telah menganut Islam pada abad ke 12 M dengan ditemukannya kuburan Nizamuddin al-Kamil yaitu seorang laksamana dari Dinasti Fatimah tahun $1123 \mathrm{M}$ (Samsu).

Kedua, Iskandar Zakaria menyatakan bahwa ketujuh orang siak berasal dari Minangkabau. Hal ini dikarenakan masyarakat Minangkabau telah memeluk Islam pada saat itu, di Minangkabau sudah banyak orang yang menunaikan ibadah haji sehingga sebutan untuk seorang ulama atau orang alim adalah syekh dan di Kerinci menjadi siak (Zakaria, Wawancara tentang Kedatangan Islam di Kerinci).

Perkembangan Islam di Kerinci dipengaruhi juga oleh Sultan Jambi. Hal ini dibuktikan adanya surat dari Sultan Jambi kepada pada Depati di Kerinci. Surat tersebut berisi tentang himbauan terhadap masyarakat Kerinci untuk memeluk agama Islam dan menghentikan kebiasaan yang berlawanan dengan Islam seperti minum tuak dan arak, serta pesta yang diiringi musik dan tarian-tarian. Surat ini masih tersimpan di Mandopo Keliling danau yang terdapat tiga surat yang berangka tahun 1776 dan 1778 (Kozok). Hal inilah yang menjadi bukti bahwa proses islamisasi di Kerinci dipengaruhi oleh Sultan Jambi, sehingga pada abad ke $19 \mathrm{M}$ masyarakat Kerinci telah menganut Islam secara keseluruhan.

Perkembangan Islam di Kerinci juga dipengaruhi beberapa ulama lokal yang berdakwah menyebarkan agama Islam seperti Buya H. Abdul Latib yang berasal dari Tanjung Tanah, beliau sangat berperan penting dalam penyebaran agama islam dengan menghilangkan beberapa kebiasaan masyarakat seperti menyabung ayam, bermain judi dan minum tuak (Martunus). Tuanku Qadi Raja yang berasal dari Semerap, yang diangkat oleh Sultan Jambi sebagai Qadi di seluruh Alam Kerinci (Agussalim), di Pulau Tengah terdapat 
berapa ulama seperti Tengku Kaluhui, H. Raha, H. Rateh dan H. Islamel yang hidup pada awal ke 19.

Meskipun di Kerinci mayoritas Islam, tetapi tidak menutup kemungkinan akan berkembangnya agama-agama non Islam. Di Kerinci saat ini terdapat beberapa agama yaitu Agama Islam, Katolik, Kristen Protestan, Hindu dan Budha. Meskipun terdapat banyak sekali agama di Kabupaten Kerinci, akan tetapi kerukunan kehidupan antar umat beragama dalam kondisi aman dan terkendali.

\section{Sejarah Batik Incung}

Jambi merupakan salah satu wilayah penghasil batik khususnya di wilayah Kerinci yang menjadi daerah penghasil batik incung. Batik ini disebut sebagai batik incung karena motif yang digunakan diambil melalui aksara incung yang merupakan aksara kuno Suku Kerinci. Hal inilah yang menjadi pembeda antara batik yang ada di wilayah Kerinci dengan wilayah lainnya yang ada di Indonesia terutama di Pulau Sumatera. Selain itu, batik di Kerinci juga menggunakan motif tumbuh-tumbuhan dan hewan yang ada di wilayah ini dengan cara menggabungkan antara motif incung dengan motif tumbuh-tumbuhan dan hewan yang ada di Kerinci (Pitri).

Perkembangan batik di Kabupaten Kerinci tidak terlepas dari peran pemerintah pada masa itu, yaitu Bambang Sukowinarno merupakan Bupati Kerinci. Pada masa pemerintahannya industri batik banyak berkembang, karena dilihat dari latar belakang bupati Kerinci pada masa itu adalah orang Jawa. Sehingga, dia mempunyai inisiatif untuk mengembangkan industri batik di Kerinci yang pada saat ini masih diproduksi di Kota Sungai Penuh. Pada saat itulah batik mulai bisa tumbuh di masyarakat Kabupaten Kerinci. Perkembangan batik di Kerinci pada saat itu dikarenakan pemerintah sedang menggali nilai budaya daerah dengan membina generasi muda sebagai ujung tombak pembangunan Kerinci pada masa yang akan datang. Batik disosialisasikan melalui pembinaan terhadap generasi muda yang bertempat di Balai Tenaga Kerja (BTK) Kerinci. (Adhanita). Untuk pengembangannya sanggar batik di Kabupaten Kerinci, para pengrajin mendapatkan bantuan dari pemerintah yaitu berupa peralatan atau sarana dan prasarana untuk membatik seperti canting, kuali kecil dan kompor untuk memanaskan malam.

Kebijakan yang dikeluarkan oleh Bupati pada tahun 1994 dengan mengikutsertakan para pengrajin batik dalam pelatihan membatik yang dilaksanakan di Yogyakarta pada tahun 1994. Selain itu, Industri batik Incung dimulai dengan pengrajinnya yang didasarkan keinginan untuk mencoba masuk ke dalam usaha batik yang dilihat memiliki peluang pasar yang cukup terbuka dan prospek kedepannya yang memadai jika melihat dari konsumen yang begitu banyak terutama dari kantor pemerintahan (Ekspres).

Perkembangan industri batik incung di Kabupaten Kerinci juga dibekali dengan pelatihan mandiri yang dilakukan oleh Elita Jaya dan Deli Iryani ke Kota Jambi. Mereka belajar pada Batik Mas ibu Marhamah selama 3 tahun. Setelah merasa sudah mampu untuk membatik sendiri, mereka kembali ke kampung halaman yaitu Kerinci untuk mengembangkan batik Kerinci. Walaupun yang dipelajari oleh pengrajin itu adalah batik Jambi, sesampai di Kerinci Elita Jaya dan Deli Iryani mulai membuat batik khas Kerinci dengan tulisan incung atau aksara kuno Kerinci dan hal inilah yang menjadi pembeda antara batik Kerinci dengan batik lainnya termasuk batik Jambi (Jaya dan Iryani). 
Pengetahuan Elita Jaya dan Deli Iryani ini untuk mengembangkan batik dengan motif incung ini juga didorong karena sudah diperkenalkannya terlebih dahulu aksara incung menjadi motif batik oleh Ida Maryanti (Dinas Perindustrian dan Perdagangan Provinsi Jambi) pada tahun 1993. Sehingga, hal ini menambah pengetahuan kedua pengusaha batik ini mampu untuk mengembangkan batik incung pada sanggar batiknya masing-masing (Kompas). Namun, motif incung mulai dimasukkan ke dalam kain mori yaitu pada tahun 1996. Motif yang digunakan oleh sanggar-sanggar batik yang ada di Kabupaten Kerinci pada masa itu adalah dengan ukiran-ukiran tradisional Kerinci.

\section{Hubungan antara Batik Incung dan Islam}

Hubungan antara batik incung dan islam di Kerinci ini terlihat dari penggunaan motif yang berkaitan dengan unsur Islam. Motif batik incung yang memiliki unsur islam ada 2 yaitu kaligrafi incung dan masjid agung Pondok Tinggi.

\section{a. Motif Kaligrafi Incung}

Motif ini memiliki makna bahwa sebagai masyarakat Kerinci dengan didominasikan oleh masyarakat yang beragama Islam untuk selalu ingat terhadap norma-norma agama dan selalu berpegang teguh terhadap Al-Quran yang menjadi pedoman hidup umat muslim. Hal ini digunakan agar masyarakat senantiasa ingat untuk melakukan perintah Allah dan meninggalkan larangannya. ${ }^{1}$
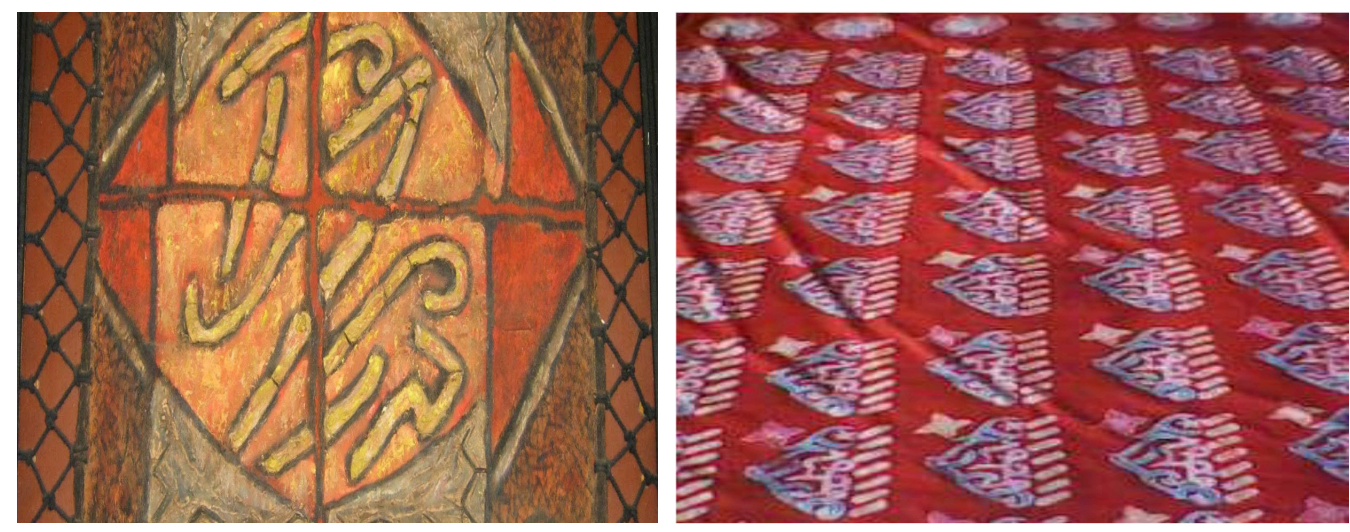

Gambar 5: Kaligrafi Incung menjadi Motif Batik

(Photo milik Elita dan diambil oleh Nandia Pitri pada 20 Juli 2018 di Sungai Penuh)

Motif ini dijadikan sebagai motif batik yaitu pada tahun 1996 oleh sanggar batik Karang Setio karena ini merupakan motif awal dari sanggar ini.

\section{b. Motif Masjid Agung Pondok Tinggi}

Masjid ini dibangun pada abad ke-18 tepatnya pada tahun 1874 dan telah berumur sekitar 140 tahun. Masjid ini dibangun secara bergotong royong oleh masyarakat dusun Pondok Tinggi pada masa itu, mulai dari kegiatan meramu dan mengambil kayu di hutan hingga pendirian masjid yang memakan waktu kurang lebih 56 tahun. Selain berfungsi sebagai

\footnotetext{
${ }^{1}$ Wawancara dengan Alimin 66 th (Budayawan Kerinci) di Sungaipenuh tanggal 28 November 2018.
} 
tempat ibadah, masjid ini juga digunakan oleh masyarakat untuk mengadakan akad nikah serta pengajian.
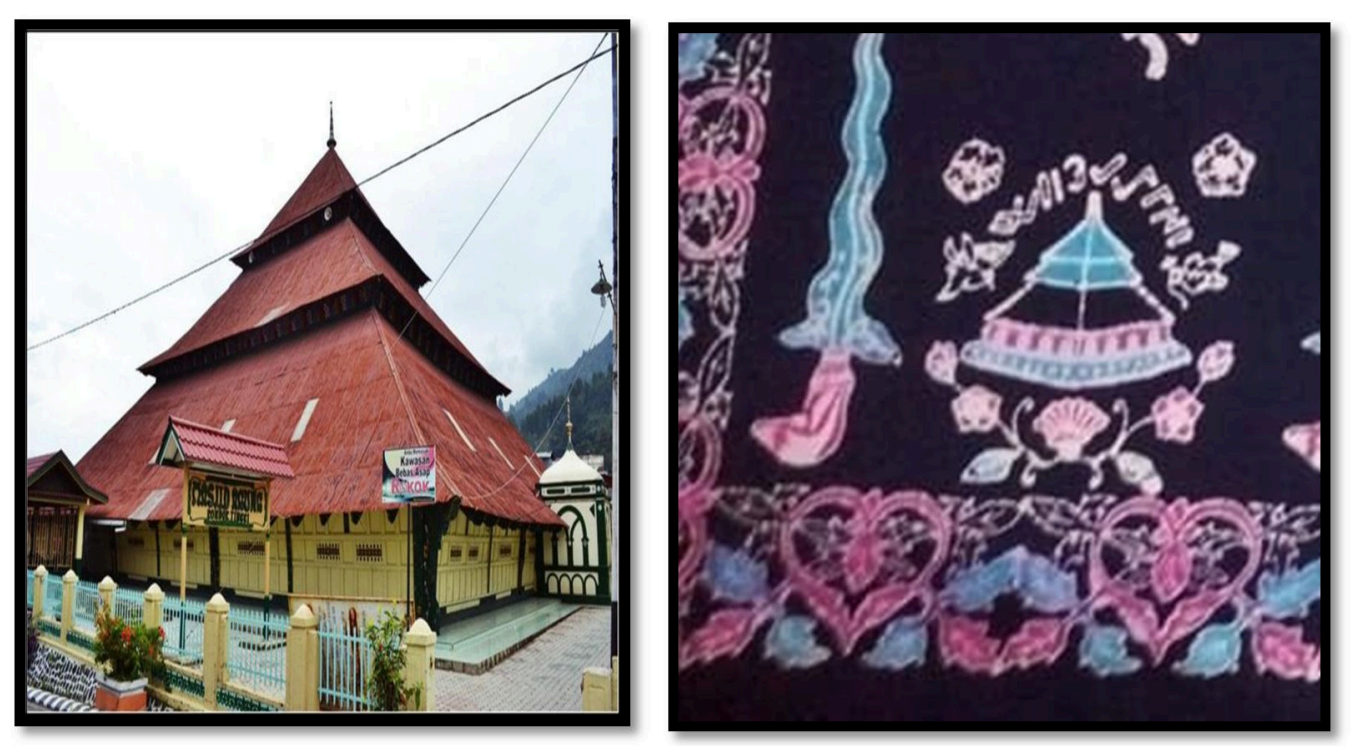

Gambar 6 : Masjid Agung Pondok Tinggi dipadukan dengan Aksara Incung menjadi Motif Batik

(Photo milik Deli dan diambil oleh Nandia Pitri 16 Juli 2018)

Motif ini dijadikan sebagai motif batik pada tahun 1999 oleh sanggar batik Puti Kincai. Ada beberapa makna yang terkandung dalam motif masjid agung Pondok Tinggi ini, pertama, "Bapucouk Satau" yang artinya Beratap satu, bangunan Masjid Agung terdiri dari satu atap, yang berarti selalu tunduk atas syarak atau aturan dari yang "Satu" ALLAH SWT dan satu pemimpin adat adat yaitu Depati Payung pondok tinggi. Kedua, "Barampek Jure" yang berarti Empat sisi, bangunan masjid yang berbentuk segi empat yang keempat sisinya mengandung makna para empat tokoh di pondok tinggi yang terdiri dari empat Rio atau Ninik Mamak, dan Empat Imam pegawai masjid yang mana berkerja sama dengan depati untuk membangun masyarakat dan agama di pondok tinggi. Ketiga, "Betingkat tige". Atap masjid yang memiliki tiga tingkatan, memiliki makna "Sko nan tige takah" atau Tiga tingkatan Pusaka di Masyarakat pondok tinggi yaitu Sko Taganai, Sko Ninik Mamak, dan Sko Depati. Dan bisa artikan masjid Agung ini dijaga layaknya pusaka bagi masyarakat pondok tinggi (Alimin, Wawancara tentang Masjid Agung Pondok Tinggi).

\section{KESIMPULAN}

Batik incung memiliki sejarah yang cukup panjang. Di dalam proses terjadinya batik incung terdapat beberapa pengaruh yang mewarnai dinamika perkambangan batik itu, yang berasal dari motif incung (aksara Kerinci kuno) yang dikolaborasikan dengan unsur islam seperti kaligrafi incung dan masjid agung Pondok Tinggi. Motif yang dituangkan dalam batik incung memiliki nilai filosofis yang tinggi. Nilai-nilai filosofi itu diambil berdasarkan kehidupan sehari-hari masyarakat Kerinci.

Batik incung yang memiliki karakteristik unik ini berkembang karena adanya dukungan pemerintah, perajin dan masyarakat setempat. Pengembangan aksara incung menjadi motif batik di Kerinci ini juga didorong oleh keinginan pemerintah untuk membuat 
batik dengan karakteristik wilayah Kerinci, maka dikembangkanlah batik incung di Kerinci sebagai batik khas Kerinci.

\section{REFERENSI}

Abdullah, Irwan. "Konstruksi dan Reproduksi Kebudayaan.” Yogyakarta: Pustaka Pelajar, 2006. 1.

Adhanita, Septiara. Pengembangan Batik Jambi Motif Sungaipenuh sebagai Bentuk Kontribusi terbadap Pembangunan. Padang: Jurnal Pembangunan Wilayah dan Kota Volume 9 (4): 381-392, 2013.

Agussalim. Wawancara tentang Perkembangan Islam di Kerinci Nandia Pitri. 27 Maret 2018.

Alimin. "Sastra Incung Kerinci." Sungaipenuh: Dinas Pariwisata dan Kebudayaan Kerinci, 2003. 4.

Alimin. Wawancara tentang Masjid Agung Pondok Tinggi Nandia Pitri. 31 Juli 2018.

Djakfar, Idris dan Idris Indra. "Menguak Tabir Prsejarah di Alam Kerinci." Sungaipenuh: Pemerintah Kabupaten Kerinci, 2001. 26.

Djakfar, Idris. "Hukum Waris Adat Kerinci.” Sungaipenuh: Pustaka Anda, 1995. 13.

Ekspres, Jambi. “Karang Setio Batik Kerinci yang Tetap Eksis.” Jambi: Jambi Ekspres, 07 Juni 1999.

Gottschalk, Louis. "Mengerti Sejarah.” Yogyakarta: Ombak, 2007. 50.

Jambi, Lembaga Adat Provinsi. "Dinamika Adat Jambi dalam Era Globalisasi." Jambi: Lembaga Adat Provinsi Jambi, 2003. 34.

Jaya, Elita dan deli Iryani. Wawancara tentang Perkembangan Batik Incung Nandia Pitri. 23 Juli 2018.

Kartini, Yayuk. "POTENSI WISATA KABUPATEN KERINCI DALAM.” 2017: 1.

Kebudayaan, Departemen Pendidikan dan. “Tambo Sakti Alam Kerinci.” Jakarta: Proyek Penerbitan Buku Sastra Indonesia dan Daerah, 1984. 29.

Kebudayaan, Dinas Pariwisata dan. "Sastra Incung Kerinci." Sungaipenuh: Dinas Pariwisata dan Kebudayaan, 2003. 1.

Kompas. "Ida Maryanti: Memindahkan 'Encong' dan Kerinci ke atas Kain Mori." Jambi: Kompas, 13 Maret 19994.

Kozok, Uli. “Kitab Undang-Undang Tanjung Tanah: Naskah Melayu yang Tertua.” Jakarta: Yayasan Obor, 2006. 56-68.

Martunus. Pemikiran Kalam Ulama Kerinci dan Implementasinya dengan Etos Kerja. Padang: Pascasarjana IAIN Imam Bonjol Padang, 2009. 
Pitri, Nandia. Sejarah Industri Batik Incung: Dari masa Kabupaten Kerinci sampai Masa Kota Sungaipenuh (1995-2017). Padang: Fakultas Ilmu Budaya Universitas Andalas, 2019.

Ramadani, Yolla. "Nilai Budaya dalam Tradisi Bapenteh pada Masyarakat Hiang Kecamatan Sitinjau Laut Kabupaten Kerinci.” Jurnal Sosial dan Humaniora, Vol 1 No. 2 Tabun 2015 (2015): 3 .

Ramli, Thahar dan Yasrina Ayu. "Biografi Mayjen H. A. Thalib (1918-1973): Perjuangan dari Bumi Sakti Alam Kerinci.” Padang: Yayasan Citra Budaya Indonesia, 2005. 1.

Samsu, Muhammad As. "Ulama Pembawa Islam di Nusantara dan Sekitarnya." Jakarta: Letera Basritama, 1999. 17.

Schrieke, B.J.O. “ Pergolakan Agama di Sumatera Barat.” Jakarta: Bharatara, 1973. 6.

Sjamsuddin, Helius. “Metodologi Sejarah.” Yogyakarta: Ombak, 2007. 121.

Syaputra, Deki ZE. Pedalaman dan Pesisir: Hubungan Kerinci dengan Jambi dan Indrapura dari tabun 1850 bingga 1921 M. Padang: Fakultas ilmu Budaya Universitas Andalas, 2018.

Vrihaspathi, Budhi Jauhari dan Ekaputra. "Senarai Sejarah Kebudayaan Suku Kerinci." Jambi: Bina Potensia Aditya Mahatva Yodha Kota Sungaipenuh dan Kabupaten Kerinci., 2013. 6.

Zakaria, Iskandar. "Tambo Sakti Alam Kerinci 3.” Sungaipenuh: Pemerintah Kabupaten Kerinci, 1985. 23.

Zakaria, Iskandar. Wawancara tentang Kedatangan Islam di Kerinci nandia Pitri. 7 Maret 2018.

Zed, Mestika. “Metodologi Sejarah.” Padang: Universitas Negeri Padang, 1999. 31. 